\section{ON BACILLUS PROTEUS INFECTION,}

MORE ESPECIALLY IN RELATION TO A CASE OF PROTEUS SEPTICZMIA ASSOCIATED WITH FEMORAL THROMBOSIS, PULMONARY EMBOLISM, AND RECOVERY.

BY CUTHBERT S. WALLACE, F.R.C.S. ENG., SURGEON TO ST. THOMAS'S HOSPITAL, LONDON;

AND

LEONARD S. DUDGEON, F.R.O.P. LOND., BACTERIOLOQIST TO ST. THOMAS'S HOSPITAL.

IN this communication we wish to record a case of considerable interest both clinically and bacteriologically, and then briefly to refer to other infections caused by proteus bacteria.

\section{The Clinical History.}

The patient, a male aged 60, suffered from complete retention from an enlarged prostate. The urine was clear and acid. A three-lobed tumour surrounded by some circumferential fibres was removed by the suprapubic route. A distinct shelf of mucous membrane was left between the bladder and the cavity from which the obstructing adenomata were removed. The course was uneventful, and the general condition of the patient was excellent, although at the end of five weeks no urine was passed by the natural route. The suprapubic sinus was enlarged, a finger introduced into the bladder, and a steel sound was passed along the urethra. It was found that the mucous membrane had healed completely over the entrance of the urethra into the bladder. The sound was pushed through and the edges of the obstructing membrane were divided radially with scissors. The patient became gravely ill, with a sustained high temperature, and very rapidly showed considerable loss of flesh. The high degree of pyrexia was associated with definite rigors. Thirteen days from the onset of this acute illness thrombosis of the deep veins of the right leg was detected, together with great codema of the surrounding tissues. On several occasions it seemed as if suppuration had supervened, owing to several very painful areas in the boggy tissue of the enormously swollen thigh. A firm, tender cord along the course of the right femoral vein could be detected for several inches. Three weeks from the onset of the thrombosis the patient developed a severe and sudden illness affecting the cardio-respiratory system, probably due to a pulmonary embolism. It is doubtful if a patient was ever in a graver condition, but once the limit of the acute illness was reached he began to improve distinctly, and the progress towards recovery was as rapid as the downward course had been. The pyrexia decreased in severity and the swelling in the leg began * diminish, so that in three and a half months from the onset he was able to return to his house in the country in a comparatively good state of health and without any visible abnormality in the legs. The act of micturition was completed in.a normal manner in every respect. The pyrexia during the height of the illness varied between $100^{\circ}$ and $105^{\circ} \mathrm{F}$., while the pulse was generally rapid and often very irregular. He never had a rash and no physical sign beyond those already referred to except an attack of tonsillitis, from which we were unable to cultivate the bacillus proteus.
Bacteriological Examination.

Blood.-A good supply of blood was obtained from a vein and various media were inoculated, including a 2 per cent. solution of bile salts in distilled water. An abundant growth of a bacillus was obtained in this medium within 24 hours, while at the end of 48 hours the other media gave a similar result. This organism, when fully investigated, was found to be identical with the bacillus cultivated from the urine.

Urine.-There was a deposit of pus, and bacilli were numerous. A sample of the urine plated direct on bile-salt lactose neutral-red agar gave' a pure culture of the bacillus about to be described in detail.

\section{Cultural Characteristics.}

Neutral-red bile-salt lactose agar.-A growth of the organism on this medium changed the colour to a yellowish brown and the individual colonies werre of a similar appearanse.

Gelatine.-Rapid liquefaction occurred.

Litmus milk.-This medium was acidified, then decolourised, and the clot which formed was rapidly peptonised.

Neutral red broth.-Marked green fluorescence was produced and the medium was altered to a canary-yellow colour.

Peptone water.-No indol formation occurred at the end of ten days.

Blood serum.-Liquefied within a few days at $37^{\circ} \mathrm{C}$.

Litmus dextrose--Acidified, decolourised, and abundant formation of gas.

Litmus cane sugar.-Acidified, decolourised, and slight production of gas.

Dulcite and maltose were acidified and decolourised, but no. gas formation occurred, while sorbite, lactose, and mannite were unaffected.

\section{Agglutination Reaction.}

A 24-hour culture of the bacillus was obtained on agar, emulsified in saline, and tested with stock antiproteus serum. The serum was prepared by immunising rabbits with filtered and boiled aggressive exudates obtained from proteus infections, as detailed in the Croonian lectures of 1912." Cultures of this bacillus isolated from the urine and blood and tested with this serum in dilutions of 1 in 10, 1 in 50, 1 in 100, and 1 in 200 gave a strong agglutination reaction both by the microscopical method and the sedimentation test. Control normal serum exerted no clumping action when treated with this bacillus in similar dilutions, while atypical members of the proteus group agglutinated to a limited degree in the presence of this serum.

\section{Pathogenicity.}

This bacillus was found to be pathogenic in guinea-pigs when injected intraperitoneally. The animals died within 24 hours from acute diffuse peritonitis. The abdominal viscera were soft and friable and mostly covered with an inflammatory exudate. In each instance a pure culture was obtained from the peritoneal exudate of a bacillus with similar cultural characters.

As regards the pathogenicity of this bacillus for guinea-pigs the results were not constant, as some animals recovered after a severe illness which cannot be regarded as an exception with bacteria of

1 Dudgeon, L. S. : The Pathology of Immunity-more especially with Regard to the Problem of Aggressins, the Croonian lectures, THE LANCET, June 15th, 22nd, and $29 \mathrm{th}$, and July 6th, 1912 
this group. When injected subcutaneously a lesion of minor importance may be excited, unless a heavy dose has been injected, when a fatal result may ensue.

Action of the Proteus Bacillus on Urine.

Samples of normal human urine were sterilised by exposure to a temperature of $60^{\circ} \mathrm{C}$. for four hours. Experiments were made by inoculating tubes of the sterile urine with this strain of proteus and incubating one batch at $37^{\circ} \mathrm{C}$. with control tubes uninoculated, and contrasting the results with similar tubes of sterile urine also inoculated with proteus, but left at room temperature. The only tubes which were altered at the end of 24 hours were those which had been inoculated and incubated at $37^{\circ} \mathrm{C}$. These were very turbid, showed a heavy deposit of triple phosphates and carbonates, and omitted a foul ammoniacal odour. It was found at the end of five days that the inoculated tubes of urine which had been left at room temperature were sterile, but when transferred to the warm incubator the urine was decom. posed in the manner indicated above. These results occurred both aerobically and anaerobically.

Horton Smith ${ }^{2}$ published some observations made by him on proteus infection of sterilised urine, and showed that the strain he was investigating decomposed the urine, setting free ammonia and precipitating triple phosphates.

The absence of decomposition of the urine at room temperature is of interest, but the rapid activity of the proteus bacillus when such samples of urine are transferred to a temperature of $37^{\circ} \mathrm{C}$. is emphasised, and such results agree with certain experiments given by McWeeney in a paper which will be referred to later. Here he states that slices of potatoes inoculated with proteus bacilli and kept at $10-12^{\circ} \mathrm{C}$. were found not to be toxic.

\section{Treatment.}

When the patient was first seen with a view to special treatment to be directed against the bacterial infection he was so desperately ill that urgent remedies had to be adopted before com. plete investigation of the case could be completed. As the infection had originated in the urinary tract and a bacillus had been cultivated from the blood stream it was supposed that we were dealing with a case of septicæmia due to the bacillus coli, a supposition which would be correct in the vast majority of similar cases. Anticoli serum was administered (50 c.c.), followed in 12 hours with 25 c.c., but without any material effect on the clinical condition or on the pyrexia. It was discovered by this time that the infecting organism belonged to the proteus group; an injection of proteus vaccine was administered, and as soon as possible the patient received the autogenous vaccine in gradually increasing doses of 15 to 30 million, while as the general condition improved the dose was increased until he finally received 500 million bacilli at each injection.

The inoculations from the first produced a distinct beneficial effect, although some rise of tem. perature occurred, while later large numbers of bacilli were administered without causing more than a slight degree of pyrexia. The improvement induced in the tissues affected by the thrombosed veins was remarkable, more especially when the acute stage of the infective process had diminished

2 Smith, P. Horton: On Bacillus Proteus Urinæ: A New Variety of the Proteus Group discovered in the Urine of a Patient Suffering from Cystitis, Juurnal of Pathology and Bacteriology, 1897, vol, iv. in intensity. In our opinion such rapid recovery from so grave an infection could have been induced only by means of a specific bacterial product.

\section{Acute and Chronic Infections Caused by Proteus Bacteria.}

For some years we have investigated various infections due to bacilli of this group, ${ }^{3}$ although the case under discussion is unique in our experience. The commonest infections caused by proteus bacilli undoubtedly are pyuria due to cystitis, non-emphysematous gangrene of infected wounds, infected sinuses, and chronic localised infective processes of various kinds. Two of the most widespread suppurative inflammations of the skin which we have ever seen were due to the proteus bacillus. In both instances these cases had been diagnosed clinically and treated as staphylococcal infections, but all to no purpose. Infection of wounds by the proteus group may be of a simple or suppurative character, and a non-emphysematous but spreading gangrene may be induced by this organism as already referred to. One of us (L. S. D.) met with a case of this kind in which the whole abdominal wound became gangrenous from an infection originating in an undiagnosed proteus pyuria. Undoubtedly the commonest infections caused by members of this group are confined to the urinary tract. It is the proteus group which produce the peculiarly offensive odour of the urine so well known in some forms of cystitis and so fully represented in the badly flushed urinals by no means uncommonly met with even at the present day. The saprophytic life of the proteus group is so fully recognised that the pathogenicity may be and often is overlooked. In fact, it is unintelligible to those who see proteus infections so often that text. books on bacteriology should give so little information on the subject.

Proteus infections as a rule are mild, occasionally severe, but the severity of the infection met with in the case under discussion is unique in our experience. Hicks ${ }^{4}$ recorded a fatal case of septicæmia from which he recovered a proteus bacillus from the blood during life and from the tissue at the necropsy. McWeeney, in an interesting paper on meat poisoning already referred to, classifies such infections into three groups, one of which he calls "the group of putrefactive aerobes (proteus)." He, however, lays too much stress on the saprophytic existence of this group of bacteria as shown by the following sentence: "We have had to deal with a group of cases referred with more or less probability to the action of organisms that lead a saprophytic existence in dead matter, and do not, as a rule, produce specific infective disease in living men or animals." In this paper reference is made to infection of meat food with proteus bacilli and to a most interesting outbreak of food poisoning recorded by Dieudonné in which 180 Prussian soldiers were infected by a potato salad found to be saturated with this organism.

A case of meningitis due to a proteus bacillus was recorded by Ross, ${ }^{6}$ and in this instance the organism in question was cultivated from the cerebro-spinal fluid during life. The proteus bacillus

3 The cultural characters of the organism described here are regarded by us as typical, bnt large numbers of strains atypical culturally and by ag as typical, but large numbers of strains

4 Hicks, J. A. B. : A Bacillus of an Unusual Kind Isolated from 4 Hicks, J. A. B. : A Bacillus of an Unusual Kind Isolt
Case of Septicæmia, The LANCET, May 3lst, 1913, p. 1526 .

McWeeney, E. T.: Meat Poisoning, its Nature, Causation, and Precention, Journal of Meat and Milk Hygiene, vol. f. 6 Ross, F. Athole: A Case of Meningitis, THE LivoeT, Nov. 9th,
1912, p. 1292. 
isolated by Ross in this case was not the typical organism according to the cultural characters given in his paper, but it had many points in common with bacteria of this family. It has been claimed that infantile diarrhoa is due to bacilli of this group, ard certain observers consider that infectious jaundice is excited by a special proteus bacillus. It should be fully recognised by clinicians that proteus bacteria are capable of exciting various infections in the human subject, mostly chronic or mild in character, but sometimes severe. The fact that this organism so often exists in the human body without exciting a severe illness has led to the belief that it is incapable of exerting a severe pathogenic effect.

\section{A SIMPLE METHOD OF TREATING}

GUNSHOT WOUNDS OF THE HUMERUS. (SUPPURATING COMPOUND COMMINUTED FRACTURE)

By PAUL BERNARD ROTH, M B., CH.B. ABERd., F.R.O.S. ENG.,

SURGEON, KENSINGTON GENERAL HOSPITAL; SENIOR ORTHOPADPC CLINICAL ASSISTANT, LONDON HOSPITAL; CAPTAIN R A.M.C (S.R.) I.C. SURGICAL DIVISION, CAMBRIDGF HOSPITAL, ALDERSHOT.

THIs method, which consists of slinging the wrist to the neck, has been in use here since the beginning of the war with complete success. On arrival at the hospital the patient is stripped to the waist, seated on a chair, and all dressings and splints removed. $\mathrm{He}$ is then instructed to take hold of the hand of the injured arm with his other hand, and slowly to bend the elbow, raising the hand as near to his neck as possible, with the elbow hanging down. The hand is then fixed there in the sling described by H. O. Thomas, of Liverpool, as the " gauge halter," but which may be conveniently called the "Thomas sling."

To apply this sling a 4-inch flannel bandage 3 yards long is knotted fairly closely round the neck, with the two ends hanging down equally. Where these two ends come opposite the upper border of the wrist, the elbow being flexed in the manner described, another knot is made, and one end passed in front of the wrist and one behind it. The wrist is now pushed snugly up against this knot, and the end which passed in front is turned up behind, and the end which passed down behind is turned up in front, and the two tied above the wrist again in a third knot. (Fig. 1.) Some wool is introduced between the bandage and the wrist to prevent chafing.

Antiseptic dressings are then applied to the wound and are kept in position around the arm with a triangular bandage. The patient is put to bed and kept propped up with pillows in a sitting position so as to allow the elbow to hang down. As soon as he feels fit enough he is encouraged to get up and sit about the ward, and even walk about in the garden, the elbow hanging down the whole while.

Though such injuries often appear hopelessly septic, with pus pouring out of the wounds of entry and exit, and with considerable tumefaction, a few days of this treatment produce a wonderful change for the better in them, and beyond enlarging the wounds and inserting a tube if the drainage is not sufficient, no further treatment besides frequently changing the dressings is required. On no account must the comminuted portions of bone be removed at this stage; most of them will heal in and help in reforming the shaft. Any fragments which necrose can be removed months later without risk then of taking away useful bone. The patient's wrist is kept in this sling night and day for five or six weeks until bony union has taken place. When the patient can voluntarily raise his hand in the sling and touch his forehead it is safe to let him come out of it.

FIa. 1.

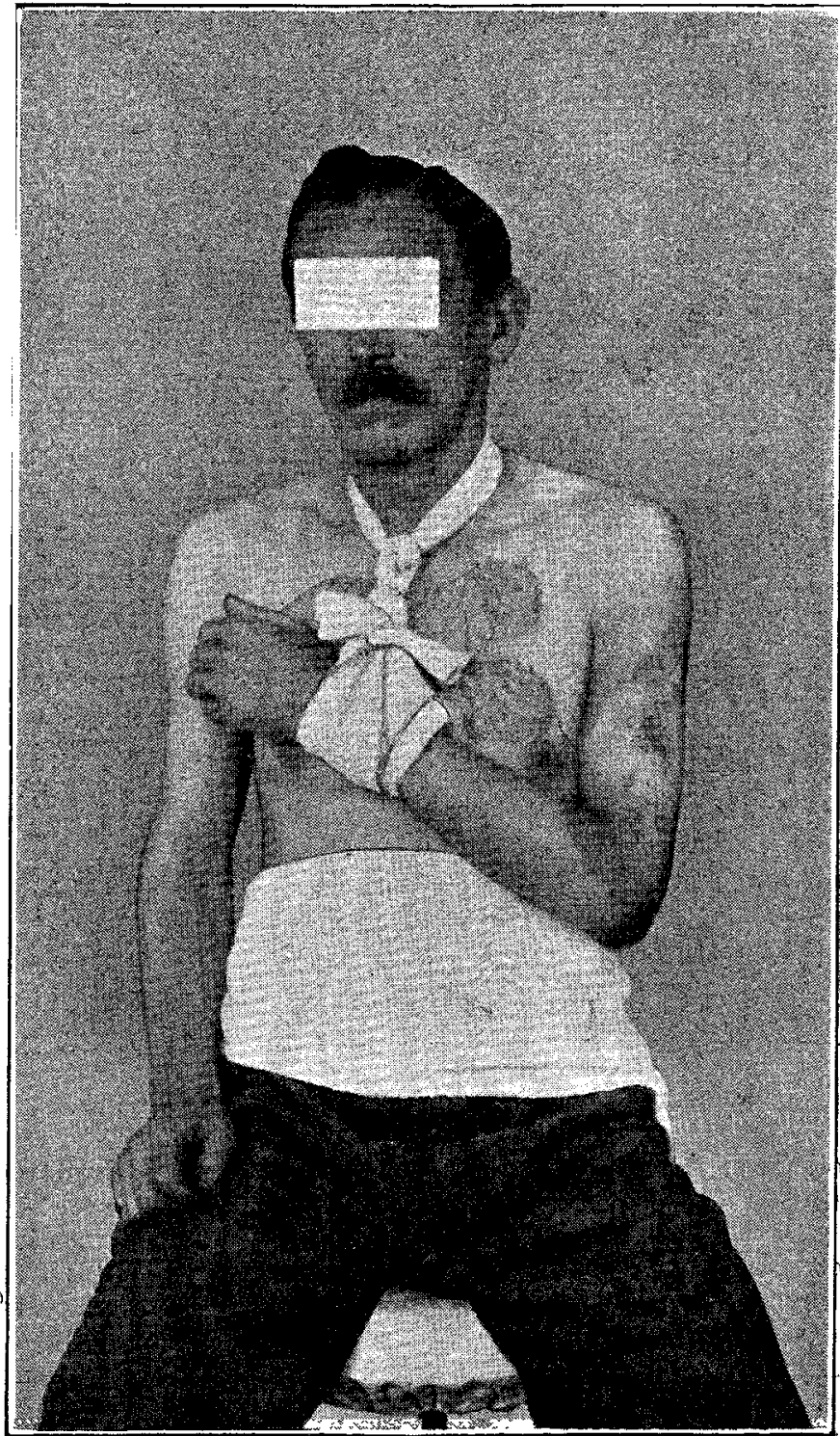

The Thomas sling in position.

If a radiogram is wanted during this period it is taken in the sling, the plate being placed between the body and the arm. When required, fresh dressings can be applied without ever taking the limb out. The patient simply leans orer in the sitting position so as to let the elbow hang clear of his side, when the dressings can be changed without disturbing the bones in any way-wherever the wounds may be situated-the whole process occupying less than a couple of minutes.

The weight of the elbow acts as a constant extending force, producing good alignment, and as there is no movement of the parts, even when the dressings are changed, the patient suffers the minimum of discomfort and is spared the pain of daily dressing which seems inseparable from other methods of treatment. By the use of this sling bony union with complete range of extension and flexion is assured. If Medical Officers with the Expeditionary Force were to adopt it, much time would be sared, much suffering avoided, and many useful limbs obtained. 